\title{
bFGF peptide combined with the pVAX-8CpG plasmid as adjuvant is a novel anticancer vaccine inducing effective immune responses against Lewis lung carcinoma
}

\author{
MENG LI $^{1 *}$, HUA SHAN SHI $^{1 *}$, HAI LONG ZHANG ${ }^{1}$, ZI CHAO LUO $^{2}$, \\ YANG WAN $^{1}$, LIAN LU ${ }^{1}$, SHUN-TAO LUO ${ }^{1}$ and LI YANG ${ }^{1}$ \\ ${ }^{1}$ State Key Laboratory of Biotherapy and Cancer Center, West China Hospital, West China Medical School, \\ Sichuan University; ${ }^{2}$ School of Life Science, Sichuan University, Chengdu, Sichuan, P.R. China
}

Received September 30, 2011; Accepted November 30, 2011

DOI: $10.3892 / \mathrm{mmr} .2011 .725$

\begin{abstract}
Due to the poor immunogenicity of subunit protein antigens, there is a need to use adjuvants in order to generate effective immune responses. Basic fibroblast growth factor (bFGF) is one of the best characterized pro-angiogenic cytokine and is a candidate target for anticancer therapy. We used truncated bFGF (tbFGF) combined with engineered pVAX$\mathrm{nCpG}$ as novel adjuvant to immunize mice in order to inhibit tumor angiogenesis and suppress tumor growth. In our study, the results demonstrated that the mice immunized with tbFGFalum-pVAX-8CpG produced a better tumor-suppression effect compared with the other groups, apart from the group treated with tbFGF-alum-CpG. In addition, the function of immune modulation of pVAX-8CpG was similar to CpG ODNs. The vaccine composed of tbFGF, alum and pVAX-8CpG effectively inhibited tumor angiogenesis and induced strong antitumor immune responses. The antitumor activity induced by the vaccine tbFGF-alum-pVAX-8CpG was not only associated with the antigen-specific antibody, but also with the killing activity of cytotoxic cells. This indicates that alum-pVAX-8CpG may be an innovative adjuvant for cancer vaccines.
\end{abstract}

\section{Introduction}

Angiogenesis is required for the growth, progression and metastasis of tumors (1-4). The process of angiogenesis is an important target with which to inhibit the growth and metastasis of solid tumors. Research suggests that tumor-associated angiogenesis is controlled by an angiogenic switch (5). There

Correspondence to: Professor Li Yang, State Key Laboratory of Biotherapy, West China Hospital, Sichuan University, Keyuan Road 4, Chengdu, Sichuan 610041, P.R. China

E-mail: yl.tracy73@gmail.com

*Contributed equally

Key words: tumor angiogenesis, truncated basic fibroblast growth factor, pVAX-nCpG, alum is a balance between inhibitors and stimulators of angiogenesis. During neoplasia, the balance is broken and shifts to an angiogenic phenotype. This change can be mediated by either an upregulation of angiogenic stimulators, such as VEGF and basic fibroblast growth factor (bFGF) or the downregulation of angiogenic inhibitors (6-8). Therefore, it is an ideal way to inhibit angiogenesis by restoring this balance to suppress tumor growth.

bFGF, an important stimulator of angiogenesis, belongs to a family of structurally related heparin-binding proteins (9-11). bFGF stimulates endothelial cell proliferation, thus promoting angiogenesis by an autocrine or paracrine manner. The role of bFGF in tumor development is demonstrated by the finding that cells transfected with the bFGF gene promote cell proliferation and angiogenesis (12-15). In summary, bFGF is a promising candidate for cancer therapy.

Since bFGF is widely expressed in normal tissues, problems exist when using wild-type bFGF as an antigen for tumor immunotherapy. For example, injected bFGF may be unable to stimulate an effective immune response but may promote angiogenesis in normal tissues or tumors. Therefore, we selected an $\mathrm{N}$ - and $\mathrm{C}$-terminally truncated human basic fibroblast growth factor (tbFGF) as an antigen which retained the original bFGF receptor-binding domains and also part of the heparin-binding domain. Research has demonstrated that tbFGF has immunogenicity but not angiogenic activity (35). However, due to its low immunogenicity when used alone $(16,17)$, we designed other strategies to obtain significant effects such as the adjunction of adjuvants.

Adjuvants play an important role in vaccine development owing to their function as immune stimulators or delivery vehicles. They modulate the immune response through immune cell recruitment and activation of immune cells to produce cytokines directly or indirectly (18). With the addition of adjuvants, the amount of antigen can be reduced and the duration of the immune response can be enhanced.

Different synthetic $\mathrm{CpG}$ oligodeoxynucleotides (ODNs) as adjuvants are currently under investigation. $\mathrm{CpG}$ island of plasmid pCDNA3.1 has been shown to enhance the immune response (19). However, the $\mathrm{CpG}$ content is contained in the coding sequence of the $\beta$-lactamase gene whose product can 
confer ampicillin resistance $(20,21)$. Thus, we constructed $\mathrm{CpG}$ content into the plasmid pVAX whose resistance gene is kanamycin. By doing so, we minimized the possibility of side effects of $\beta$-lactamase. The present study is the first to investigate the function of pVAX-nCpG in tumor immunotherapy. We observed that the $\mathrm{CpG}$ constructed in the plasmid pVAX had a similar function with synthetic CpG ODNs. CpG ODNs have been reported to promote antigen-specific responses including the direct activation of $\mathrm{B}$ cells and dendritic cells (DCs) through TLR9 triggering, increasing antigen cross-presentation by DCs and secretion of Th1 cytokines (22-26).

Alum is the only adjuvant approved for use in humans. Increased evidence has demonstrated its depot effect leading to a prolonged antigen exposure thus enhancing activation of the immune system (27-29). Alum is safe and well-tolerated but is relatively weak as an adjuvant. Therefore, it should be used with other adjuvants.

Here, we researched a novel vaccine adjuvant comprising a mixture of pVAX-8CpG and alum which effectively enhanced the immunogenicity of tbFGF. The in vitro and in vivo performance of this complex indicates its potential as a new vaccine adjuvant.

\section{Materials and methods}

Vaccine preparation. The tbFGF peptide was obtained by expression and purification according to previous reports (30-33). Briefly, the tbFGF cDNA was engineered into a prokaryotic expression plasmid PQE30 (Qiagen Inc., Valencia, CA, USA) to obtain $6 \mathrm{X}$ His and the tbFGF fusion protein. The fusion protein was expressed in TG-1 as a soluble protein. Cells were lysed using high-pressure homogenization (APV 2000, Denmark). The purification of tbFGF used two processes of SP-ion-exchange chromatography and Ni-chelating sepharose affnity chromatography. An ' $n$ ' number of $\mathrm{CpG}$ (5'-TCGTCGTTTTGTCGTTTTGTCGTT-3') were cloned into the vector pVAX by Invitrogen (Fig. 1).

Cell and cell cultures. Lewis lung carcinoma (LL2) cells and NIH-3T3 fibroblasts, purchased from the American Tissue Culture Collection (ATCC), were cultured in Dulbecco's modified Eagle's medium (Gibco BRL, Grand Island, NY, USA) supplemented with $10 \% \mathrm{FBS}$ and $100 \mu \mathrm{g} / \mathrm{ml}$ of amikacin and maintained in a humidified chamber at $37^{\circ} \mathrm{C}$ in a $5 \% \mathrm{CO}_{2}$ atmosphere.

Mice. Female 8-week-old C57 mice, purchased from the West China Experimental Animal, were maintained at the Animal Center of the State Key Laboratory of Biotherapy of Sichuan University. The experimental protocol was approved by the Ethics Review Committee for Animal Experimentation of the State Key Laboratory of Biotherapy of Sichuan University.

Animal experiment. C57BL/6 mice ( $\mathrm{n}=6 /$ group) were vaccinated s.c. 3 times (at 1, 3 and 5 weeks) with the tbFGF peptide (20 $\mu \mathrm{g} /$ dose) $)$ together with alum (50 $\mu \mathrm{l} / \mathrm{dose}), \mathrm{CpG}(20 \mu \mathrm{g} /$ dose), alum-pVAX (alum $50 \mu \mathrm{l} / \mathrm{dose}$, pVAX $20 \mu \mathrm{g} /$ dose), the alum-pVAX-4CpG complex (alum $50 \mu \mathrm{l} / \mathrm{dose}$, pVAX-4CpG $20 \mu \mathrm{g} / \mathrm{dose}$ ) or the alum-pVAX-8CpG complex (alum $50 \mu \mathrm{l} /$ dose, pVAX-8CpG $20 \mu \mathrm{g} / \mathrm{dose}$ ) or with PBS alone as a control.

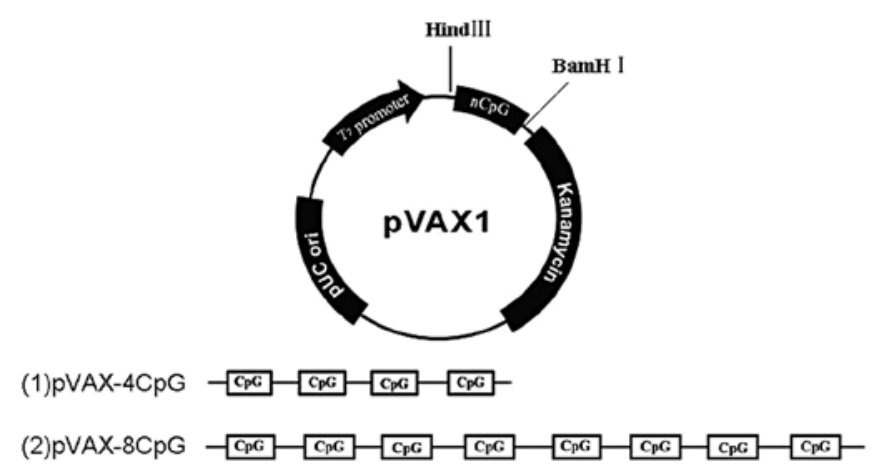

Figure 1. The construction of pVAX-nCpG. Either 4 or $8 \times \mathrm{CpGs}$ (5-TCGTCGTTTTGTCGTTTTGTCGTT-3') were cloned into the HindIII/ BamHI sites in the pVAX vector without a linker.

One week after the third immunization, mice were challenged with LL2 cells. The tumor cells $\left(5 \times 10^{5}\right)$ were injected s.c. in the back in the subcutaneous model. The subcutaneous tumor volume was measured every three days. Mice were euthanized when tumors reached $>2000 \mathrm{~mm}^{3}$. In contrast, tumor cells $\left(5 \times 10^{5}\right)$ were injected into mice by the tail vein in the metastasis model. Twenty-eight days after the LL2 cells were injected, the mice were sacrificed. Lungs were obtained and the tumor nodes were counted and analyzed.

Detection of the antibody titer and neutralizing antibody titer. Serum was obtained from mice of every group at week $0,1,2,3,4,5$ and 6 . Specific anti-bFGF antibodies were measured by ELISA. Briefly, microwell plates (Nunc, USA) were coated with bFGF protein [(100 $\mu \mathrm{l}) 1 \mu \mathrm{g} / \mathrm{ml}$ in $50 \mathrm{mM}$ carbonate/bicarbonate buffer $(\mathrm{pH}=9.6)]$ at $4^{\circ} \mathrm{C}$ overnight. The coated plates were washed three times with PBS/Tween-20. The plates were then blocked with $5 \%$ non-fat dry milk and $0.05 \%$ Tween- 20 in PBS for $1 \mathrm{~h}$ at $37^{\circ} \mathrm{C}$. After being washed five times with PBS/Tween-20, the plates were incubated with serial dilutions of anti-sera from vaccinated animals for $1 \mathrm{~h}$ at $37^{\circ} \mathrm{C}$. Naïve mouse serum was used as the negative control. Plates were washed and incubated with peroxidase-labeled goat anti-mouse IgG (ZSGB-BIO, Beijing, China) for $1 \mathrm{~h}$ at $37^{\circ} \mathrm{C}$. Following the washing, the substrate (KPL) was added and incubated for $15 \mathrm{~min}$ at $37^{\circ} \mathrm{C}$. The colorimetric reaction was stopped with $0.5 \mathrm{M} \mathrm{H}_{2} \mathrm{SO}_{4}$. The absorbance was read by a Bio-Rad microplate reader at $450 \mathrm{~nm}$.

One week after the last immunization, the mice were bled, and the serum was used for neutralizing antibody assay. The neutralizing antibody was determined using a neutralizing bioassay using NIH-3T3 fibroblasts as target cells. In this bioassay, bFGF was pre-incubated with a serial dilution of serum for $1 \mathrm{~h}$ at $37^{\circ} \mathrm{C}$. Then, the antigen-antibody mixture was added to cultures of NIH-3T3 cells in DMEM with 2\% FBS in 96-well microplates. After being incubated for $72 \mathrm{~h}$ in a $5 \% \mathrm{CO}_{2}$ humidified incubator, MTT was added and incubation was carried out for an additional $5 \mathrm{~h}$. After lysis buffer was added, the plates were measured at an absorbance of $595 \mathrm{~nm}$ in a Bio-Rad microtiter plate reader.

Cytotoxicity assays. One week after the third immunization, splenic lymphocytes were isolated and stimulated with the 
A

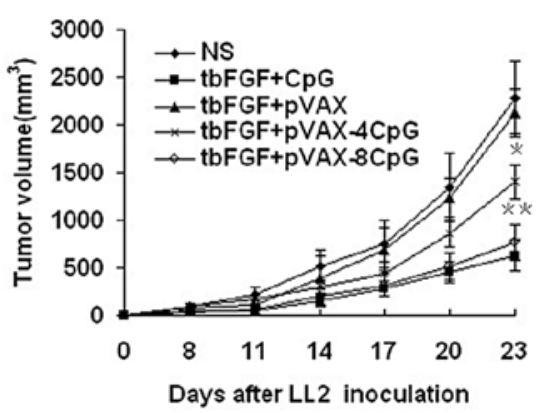

B

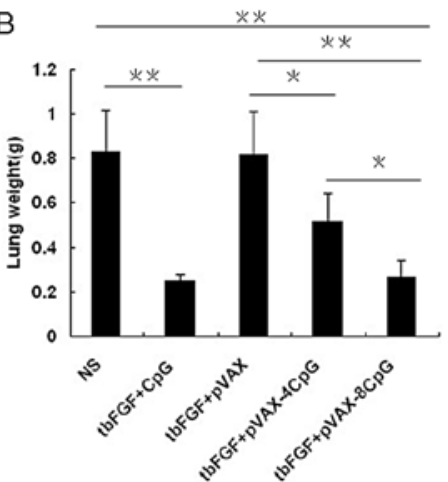

C

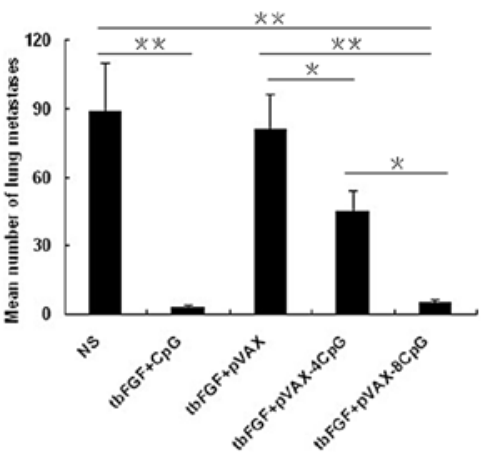

Figure 2. Anti-tumor effect in vivo. (A) After three immunizations at week 1, 3 and 5, the mice were challenged s.c. with LL2 cells at week 7, and the tumors were measured every third week. (B) The lung metastasis model was established by injecting i.v. 5x10 5 LL2 cells into the mice. (C) Twenty-eight days after tumor cell inoculation, mice were sacrificed and the lung weights and the number of lung metastases were assessed. Similar results were obtained in three independent experiments. ( $\left.\mathrm{P}<0.05,{ }^{* *} \mathrm{P}<0.01\right)$.

tbFGF peptide $(10 \mu \mathrm{g} / \mathrm{ml})$ for the analysis of specific cytolytic activity. Briefly, LL2 cells were labeled with ${ }^{51} \mathrm{Cr}$ for $1.5 \mathrm{~h}$ at $37^{\circ} \mathrm{C}$. After being washed three times, the fixed amount of ${ }^{51} \mathrm{Cr}$-labeled target cells $\left(1 \times 10^{4}\right)$ were co-cultured with serially diluted splenic lymphocytes in RPMI-1640 with 10\% FCS in 96-well tissue culture plates. After co-culturing for $4 \mathrm{~h}$, the supernatants were collected and radioactivity was measured using a gamma-counter. CTL killing was calculated using the following equation: (Experimental release - spontaneous release)/(maximum release - spontaneous release) x 100 .

Histological analysis. After mice were sacrificed, the xenograft specimens were obtained and embedded in OCT compound and frozen, and the $5-\mu \mathrm{m}$ sections were cut with a cryostat microtome. Apoptosis was studied by dead-end colorimetric terminal deoxynucleotidyl transferase-mediated dUTP nick-end labeling (TUNEL) system (Promega, Madison, WI, USA) according to the manufacturer's protocol. The apoptotic index was evaluated by calculating the mean ratio of labeled cells in 1000 cells in the upper, middle and basal zones of at least five crypts.

The quantification of microvessel density (MVD) was evaluated by the method of Weidner et al (32). Briefly, sections were washed in PBS and incubated for 20 min with $3 \% \mathrm{H}_{2} \mathrm{O}_{2}$ and for an additional 20 min with $0.2 \%$ Triton X-100 in PBS. Then, a 20-min preincubation with diluted normal serum was followed by incubation with the anti-CD31 antibody (1:200; Santa Cruz Biotechnology, Santa Cruz, CA, USA) at $4^{\circ} \mathrm{C}$ overnight. Sections were then incubated with the biotinylated secondary antibody (1:100; Santa Cruz Biotechnology) and the avidin-biotin-peroxidase complex (Dako AB Complex HRP) for $30 \mathrm{~min}$. The peroxidase color reaction was developed with DAB substrate, and the sections were lightly counterstained with Mayer's hematoxylin.

Toxicity. Drug toxicity indices were closely observed during the entire treatment, such as weight loss. In order to clarify potential side effects of our vaccines, tissues of the heart, liver, spleen, lung and kidney were fixed, embedded in paraffin and sliced. Sections were stained with hematoxylin and eosin and observed using the double-blind method.
Statistical analysis. Statistical comparisons were performed with SPSS, using the one-way ANOVA for comparisons of multiple group data sets, and analysis of variance of multiple comparisions. The threshold of significance was set at $\mathrm{P}<0.05$.

\section{Results}

Anti-tumor effect of tbFGF-alum-pVAX-8CpG. The ability of the C57BL/6 mice immunized with the vaccines to reject tumors in vivo was further assessed. In the study, the subcutaneous model and lung metastasis model using LL2 cells were established. As shown in Fig. 2A, in the subcutaneous model, LL2 cells grew rapidly in the mock buffer-treated and tbFGF-alum-pVAX-treated animals, with tumors reaching $2480 \mathrm{~mm}^{3}$ by Day 23, at which time mice were sacrificed. The mice immunized with tbFGF-alum-pVAX-4CpG exhibited inhibition of tumor growth to some extent, while the mice immunized with tbFGF-alum-pVAX-8CpG had significantly stronger anti-tumor capacity. In the metastasis model, the lung weight and the number of tumor nodes in the lungs of the mice immunized with tbFGF-alum-pVAX-8CpG or tbFGF-alum-CpG were significantly less than those in the other groups (Fig. 2B and C). This indicated that vaccination comprised of the tbFGF peptide, alum and $\mathrm{pVAX}-8 \mathrm{CpG}$ induced a potent bFGF-specific immune response in vivo sufficient to inhibit the growth and metastasis of LL2.

Detection of the anti-bFGF total antibody and neutralizing antibody. At week 0, 1, 2, 3, 4, 5 and 6, serum from the C57 mice immunized with the tbFGF peptide, together with alum, $\mathrm{CpG}$, alum-pVAX, the alum-pVAX-4CpG complex or the alum-pVAX-8CpG complex, were analyzed by ELISA for the presence of total specific anti-bFGF IgG (Fig. 3A). The tbFGF peptide combined with alum-pVAX failed to induce a strong immune response even after the third immunization, while the co-formulation of the tbFGF peptide with alum$\mathrm{CpG}$, alum-pVAX-4CpG or alum-pVAX-8CpG resulted in significantly higher titers of total IgG and sustained increase after the first immunization. The anti-bFGF titers in the three groups were not significantly different. We then analyzed the neutralizing antibody titer to tbFGF in each group. 

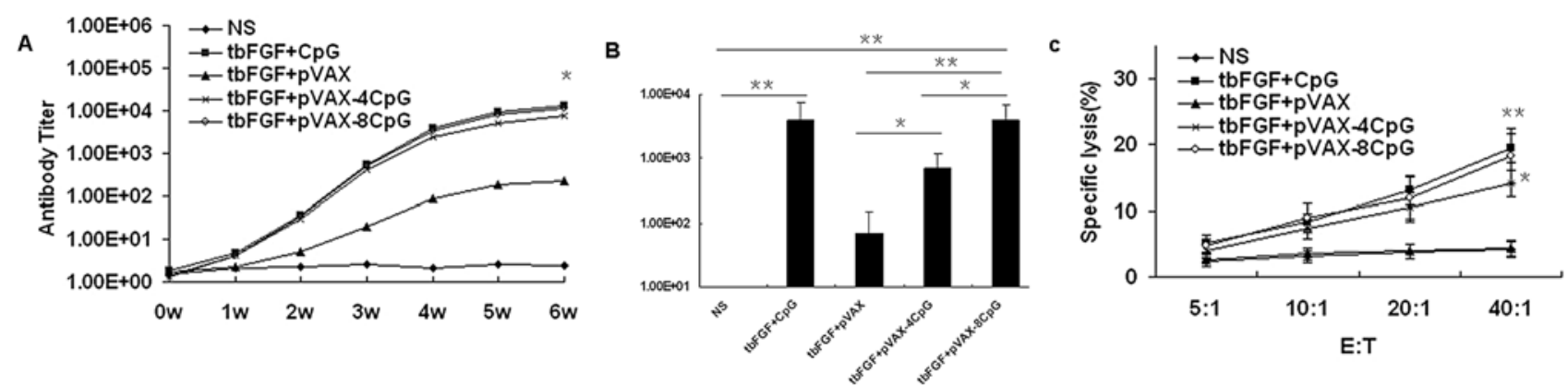

Figure 3. Detection of specific anti-tbFGF antibodies and specific lysis assay. C57 mice were immunized as described in the text. (A) At week 0, 1, 2, 3, 4, 5 and 6, serum was collected and the specific anti-tbFGF total IgG antibody titer was measured by ELISA. (B) One week after the last immunization, the mice were bled and serum was used for the neutralizing antibody assay. The neutralizing antibody was determined in a neutralizing bioassay using NIH-3T3 fibroblasts as target cells. (C) One week after the third immunization, the splenocytes from every group were separated and used as effectors for the specific lysis assay. Fixed amount of ${ }^{51} \mathrm{Cr}$-labeled LL2 cells $\left(1 \times 10^{4}\right)$ were used as target cells. The ratios of splenocytes to LL2 were 5:1, 10:1, 20:1, 40:1. The assay was run in three replicates.

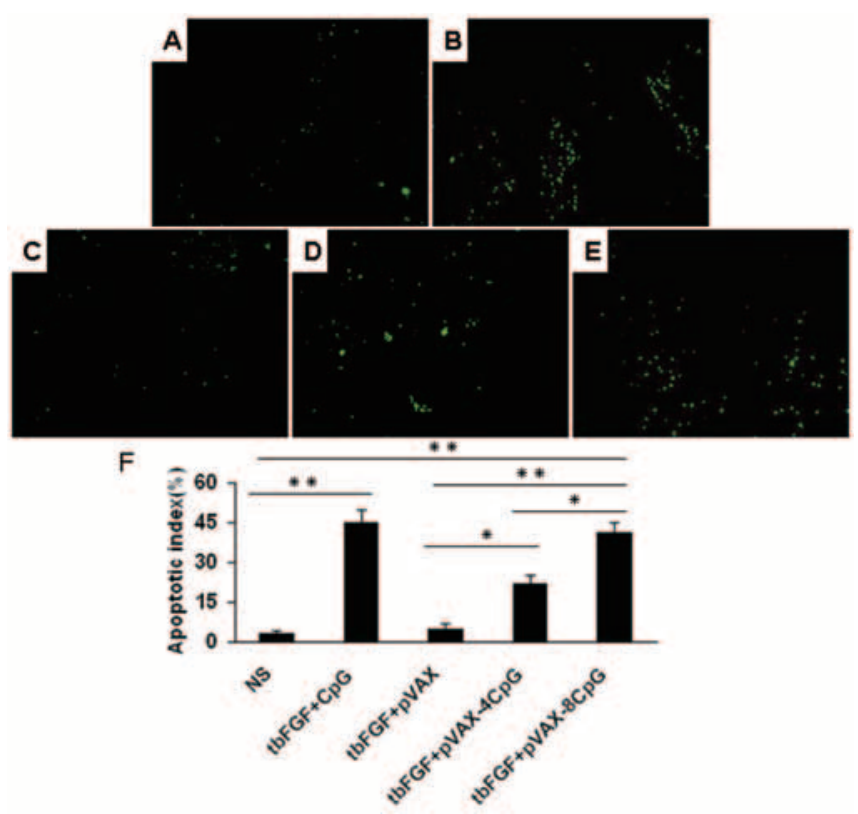

Figure 4. Detection of apoptosis of the tumor tissues by TUNEL staining. Sections of frozen LL/2 tumor tissues were stained with FITCdUTP, which were obtained from mice immunized with (A) PBS, (B) tbFGF-CpG, (C) tbFGF-alum-pVAX, (D) tbFGF-alum-pVAX-4CpG or (E) tbFGF-alum-pVAX-8CpG, respectively (original magnification, $\mathrm{x} 200$ ). (F) Apoptotic index in each group was evaluated by the mean ratio of labeled cells in 1,000 cells in at least five crypts.

Neutralizing antibody was not detected in the control group. Mice immunized with tbFGF-alum-pVAX generated low titers of the neutralizing antibody, while the addition of pVax$4 \mathrm{CpG}$ led to only a slight improvement. Neutralizing antibody generated in the groups immunized with tbFGF-alum-CpG or tbFGF-alum-pVAX-8CpG was significantly higher compared with the other groups. However, the neutralizing antibody titer in mice immunized with tbFGF-alum-pVAX-8CpG was similar to that in the tbFGF-alum-CpG group (Fig. 3B).

Cytotoxicity assays. ${ }^{51} \mathrm{Cr}$ release assay was used to detect the specific cytotoxicity mediated by CTL. There was no change in the specific lysis rate with the increasing addition of effectors in the groups treated with PBS or tbFGF-alum-

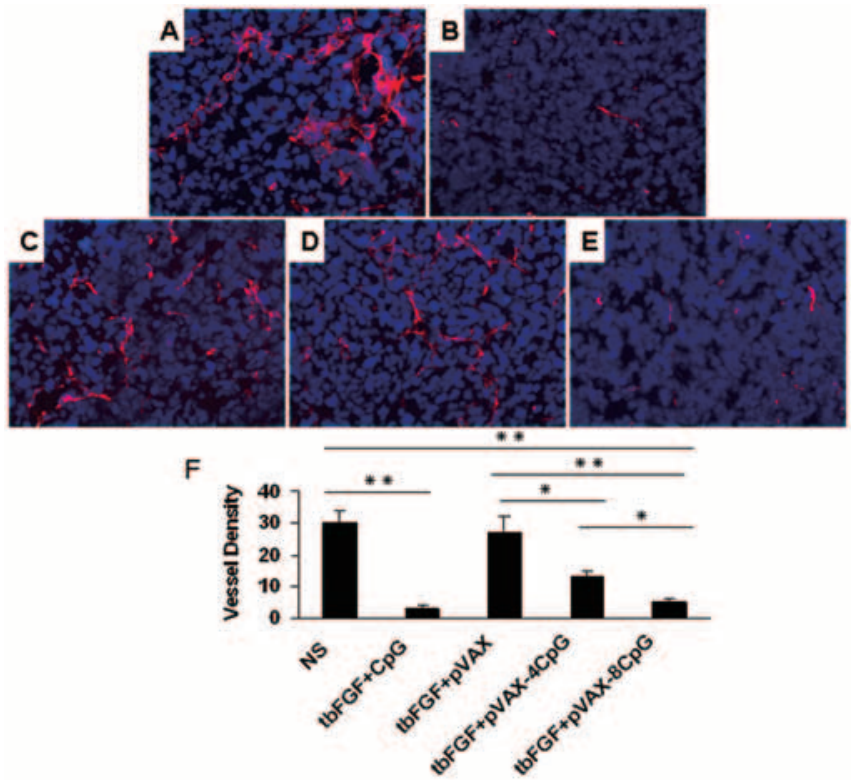

Figure 5. Inhibition of angiogenesis within the tumor was evaluated by CD31 staining. Tumor tissues were stained with antibodies to CD31, which were obtained from mice treated with (A) PBS, (B) tbFGF-CpG, (C) tbFGF-alumpVAX, (D) tbFGF-alum-pVAX-4CpG and (E) tbFGF-alum-pVAX-4CpG, respectively. (F) Vascular density in each group. Vessel density was determined by counting the number of microvessels per high-power field (magnifcation, x400).

pVAX. The specific lysis rate in the group treated with tbFGF-alum-pVAX-4CpG was higher. Splenic cells from the mice treated with tbFGF-alum-pVAX-8CpG exhibited significantly increased cytotoxicity to LL2 cells compared with the other groups except tbFGF-alum-CpG (Fig. 3C). This finding indicates that there was an enhancement of specific antitumor cellular immunity by the addition of pVAX-8CpG. There was no significant difference between the group treated with tbFGF-alum-pVAX-8CpG and the group immunized with tbFGF-alum-CpG in regards to specific cytotoxicity.

Increase in apoptosis and inhibition of tumor-induced angiogenesis in vivo. In order to evaluate the apoptosis in 
tumor tissues, the tumor sections were stained with TUNEL reagent (Fig. 4). More apoptotic cells were noted in the tumors from the tbFGF-alum-pVAX-4CpG group than those in the control group. Apparent necrosis was observed in the tbFGF-alum-pVAX-8CpG group. Furthermore, substantially more apoptotic cells were observed in the tumor sections of mice immunized with tbFGF-alum-pVAX-8CpG than in the group treated with PBS, bFGF-alum-pVAX or bFGF-alumpVAX-4CpG. The apoptotic index also revealed that LL2 of mice immunized with tbFGF-alum-pVAX-8CpG displayed higher indices than in these groups. The microvascular density (MVD) of the tumor sections were used to determine whether the increased apoptosis was associated with anti-angiogenesis in the mice immunized with tbFGF-alum-pVAX-8CpG. Each tumor section was stained with anti-CD31 antibody (Fig. 5). Tumors of the mice immunized with tbFGF-alum-pVAX8CpG exhibited smaller microvessel counts than the other groups apart from the group immunized with tbFGF-alumCpG (Fig. 5). There was no significant difference between the tbFGF-alum-pVAX-8CpG group and the tbFGF-alum-CpG group in regards to the vessel density of the tumors. These results indicate that the decreased tumor volumes of the tbFGFalum-pVAX-8CpG group may have been caused by increased apoptosis, which was associated with anti-angiogenesis.

Toxicity. In the present study, compared with the control groups, no significant differences were observed in gross measures. Furthermore, no pathologic changes were found in heart, liver, lung, spleen and kidney (data not shown).

\section{Discussion}

Tumors remain in a dormant phase for a long time until the initiation of tumor vasculature formation. Tumors can only grow to $\sim 2 \mathrm{~mm}$ in size without a provision of blood vessels as diffusion is sufficient at this level to supply nutrients to tumor cells and remove wastes $(1,33)$. Therefore, the process of angiogenesis is an important target to inhibit the growth and metastasis of solid tumors.

After more than three decades of intensive study, a large number of research has revealed that bFGF plays an important role in tumor angiogenesis. Hori et al reported that an anti-bFGF monoclonal antibody was capable of inhibiting angiogenesis and tumor growth (34). Inoue et al demonstrated that Ad-bFGF-AS successfully inhibited the growth of established human TCC xenografts by downregulating the expression of bFGF and MMP-9 by the tumor cells (35). Moreover, Plum et al indicated that the heparin binding domain peptide of bFGF combined with a liposome/adjuvant effectively inhibited angiogenesis and tumor growth in murine B16 melanoma and Lewis lung carcinoma (10). Therefore, a powerful approach for cancer treatment to inhibit tumor-associated angiogenesis is the targeting bFGF.

bFGF is a candidate target antigen in cancer immunotherapy. However, various problems present in the bFGF protein vaccine. Studies have reported that administration of exogenous bFGF induced many types of responses in vivo. For example, bFGF has been shown to induce rapid neovascularization in the kindey capsule or in the skin $(14,36,37)$. Furthermore, free bFGF in the body has the potential to promote tumor vessel growth (19). Therefore, we used a $\mathrm{N}$ - and C-terminal tbFGF peptide for immunotherapy.

Due to the poor immunogenicity of the tbFGF peptide, it is difficult to obtain an effective immune response by injecting the tbFGF peptide alone. The addition of adjuvants is required. CpG ODNs, mimics of the $\mathrm{CpG}$ motifs present in bacterial DNA, can stimulate the host's innate immune system, promote the transition to adaptive immunity and enhance immunogenicity. CpG ODNs have been shown to overcome the type II bias associated with conventional adjuvants such as alum (38-40).

The $\mathrm{CpG}$ island in the plasmid pcDNA3.1 has been shown to enhance immune response to tbFGF (19). Because of some defects of pcDNA3.1, it is difficult to apply this plasmid in clinical trails. Therefore we carried out various improvement in order to find a novel adjuvant which is not only effective but also safe. In our study, pVAX-nCpG was constructed by inserting $\mathrm{nCpG}$ into the plasmid vector pVAX in order to substitute $\mathrm{CpG}$ ODNs as a novel adjuvant. pVAX, a transformation of pCDNA3.1, is in line with the relevant requirements of FDA DNA vaccine requirements. pVAX-8CpG demonstrated a similar immunomodulatory activity to $\mathrm{CpG}$ ODNs. However, there are some advantages of pVAX-8CpG compared with $\mathrm{CpG}$ ODNs. Its cost is lower and large-scale production is easier to achieve. Furthermore, the half-life of $\mathrm{CpG}$ can be extended by being cloned in the vector. In short, pVAX-8CpG may be a novel effective adjuvant for cancer vaccines.

In the Lewis lung carcinoma model, the vaccine comprised of the tbFGF peptide, alum and pVAX-8CpG stimulated an effective bFGF-specific anti-tumor immune response. TUNEL and CD31 staining showed an obvious reduction in MVD in the group immunized with tbFGF-alum-pVAX-8CpG. Obviously, the vaccine comprised of the tbFGF peptide, alum and pVAX$8 \mathrm{CpG}$ stimulated a bFGF-specific immune response sufficient to increase tumor apoptosis and inhibit tumor-induced angiogenesis, leading to inhibition of tumor growth. In summary, the adjuvant combination of alum and pVAX-8CpG induces potent and long-lasting antigen specific humoral and cellmediated immune responses in vivo, and may provide a better and safer alternative to conventional adjuvants.

\section{Acknowledgements}

This study was supported by the Program for New Century Excellent Talents in the University (NCET) (NCET-09-0575) and the National Natural Science Foundation of China (grant nos. 30973453 and 31070815).

\section{References}

1. Folkman J: Tumor angiogenesis: therapeutic implications. N Engl J Med 285: 1182-1186, 1971.

2. Makrilia N, Lappa T, Xyla V, Nikolaidis I and Syrigos K: The role of angiogenesis in solid tumors: an overview. Eur J Intern Med 20: 663-671, 2009.

3. Han H, Silverman JF, Santucci TS, et al: Vascular endothelial growth factor expression in stage I non-small cell lung cancer correlates with neoangiogenesis and a poor prognosis. Ann Surg Oncol 8: 72-79, 2001.

4. Sridhar SS and Shepherd FA: Targeting angiogenesis: a review of angiogenesis inhibitors in the treatment of lung cancer. Lung Cancer 42: S81-S91, 2003. 
5. Liotta LA, Steeg PS and Stetler-Stevenson WG: Cancer metastasis and angiogenesis: an imbalance of positive and negative regulation. Cell 64: 327-336, 1991.

6. Bikfalvi A, Javerzat S, Perollet C and Savona C: Angiogenesis and cancer. Bull Cancer 84: 885-890, 1997.

7. Bouck N, Stellmach V and Hsu SC: How tumors become angiogenic. Adv Cancer Res 69: 135-174, 1996.

8. Yang LP, Cheng P, Peng XC, et al: Anti-tumor effect of adenovirusmediated gene transfer of pigment epithelium-derived factor on mouse B16-F10 melanoma. J Exp Clin Cancer Res 28: 75, 2009.

9. Beenken A and Mohammadi M: The FGF family: biology, pathophysiology and therapy. Nat Rev Drug Discov 8: 235-253, 2009.

10. Plum SM, Holaday JW, Ruiz A, Madsen JW, Fogler WE and Fortier AH: Administration of a liposomal FGF-2 peptide vaccine leads to abrogation of FGF-2-mediated angiogenesis and tumor development. Vaccine 19: 1294-1303, 2000.

11. Neufeld G, Mitchell R, Ponte P and Gospodarowicz D: Expression of human basic fibroblast growth factor cDNA in baby hamster kidney-derived cells results in autonomous cell growth. J Cell Biol 106: 1385-1394, 1988.

12. Rogelj S, Weinberg RA, Fanning P and Klagsbrun M: Basic fibroblast growth factor fused to a signal peptide transforms cells. Nature 331: 173-175, 1988.

13. Sasada R, Kurokawa T, Iwane $\mathrm{M}$ and Igarashi K: Transformation of mouse BALB/c 3T3 cells with human basic fibroblast growth factor cDNA. Mol Cell Biol 8: 588-594, 1988.

14. Miyake H, Hara I, Yoshimura K, et al: Introduction of basic fibroblast growth factor gene into mouse renal cell carcinoma cell line enhances its metastatic potential. Cancer Res 56: 2440-2445, 1996

15. Garlapati S, Facci M, Polewicz M, et al: Strategies to link innate and adaptive immunity when designing vaccine adjuvants. Vet Immunol Immunopathol 128: 184-191, 2009.

16. Liu Y, Sun L, Huan Y, Zhao H and Deng J: Application of bFGF and BDNF to improve angiogenesis and cardiac function. J Surg Res 136: 85-91, 2006.

17. Zhang HL, Yuan C, Zhang DM, et al: A novel combined conjugate vaccine: enhanced immunogenicity of bFGF with CRM197 as a carrier protein. Mol Med Rep 4: 857-863, 2011.

18. Ballas ZK, Rasmussen WL and Krieg AM: Induction of NK activity in murine and human cells by $\mathrm{CpG}$ motifs in oligodeoxynucleotides and bacterial DNA. J Immunol 157: 1840-1845, 1996.

19. Zhang XP, Yang L, Shi HS, et al: An N-, C-terminally truncated basic fibroblast growth factor and LPD (liposome-polycationDNA) complexes elicits a protective immune response against murine colon carcinoma. Cancer Biol Ther 10: 276-281, 2010.

20. Ni Y, Ma K, Ni J, Zheng X, Wang Y and Xiong S: A rapid and simple approach to preparation of monoclonal antibody based on DNA immunization. Cell Mol Immunol 1: 295-299, 2004.

21. Zhang HY, Sun SH, Guo YJ, et al: Immune response in mice inoculated with plasmid DNAs containing multiple-epitopes of foot-and-mouth disease virus. Vaccine 21: 4704-4707, 2003.

22. Bendigs S, Salzer U, Lipford GB, Wagner H and Heeg K: CpG-oligodeoxynucleotides co-stimulate primary $\mathrm{T}$ cells in the absence of antigen-presenting cells. Eur J Immunol 29: 1209-1218, 1999

23. Hartmann G, Weiner GJ and Krieg AM: CpG DNA: a potent signal for growth, activation, and maturation of human dendritic cells. Proc Natl Acad Sci USA 96: 9305-9310, 1999.
24. Krieg AM: CpG motifs in bacterial DNA and their immune effects. Annu Review Immunol 20: 709-760, 2002.

25. Krieg AM and Davis HL: Enhancing vaccines with immune stimulatory CpG DNA. Curr Opin Mol Ther 3: 15-24, 2001.

26. Kovacs-Nolan J, Latimer L, Landi A, et al: The novel adjuvant combination of $\mathrm{CpG} \mathrm{ODN}$, indolicidin and polyphosphazene induces potent antibody- and cell-mediated immune responses in mice. Vaccine 27: 2055-2064, 2009.

27. Lindblad EB: Aluminium compounds for use in vaccines Immunol Cell Biol 82: 497-505, 2004.

28. HogenEsch H: Mechanisms of stimulation of the immune response by aluminum adjuvants. Vaccine 20: S34-S39, 2002

29. Preparation of anionic poly (epsilon-caprolactone)-poly (ethylene glycol)-poly (epsilon-caprolactone) copolymeric nanoparticles as basic protein antigen carrier. Growth Factors 25: 202-208, 2007.

30. Chen X, Wang X, Wang Y, et al: Improved tumor-targeting drug delivery and therapeutic efficacy by cationic liposome modified with truncated bFGF peptide. J Control Release 145: 17-25, 2010

31. Luo Z, Peng X, Shi H, Gong C, Qian Z and Yang L: Comparison of the protective effects of truncated bFGF and native bFGF against murine lung carcinoma. Int J Mol Med 28: 3-8, 2011.

32. Weidner N, Semple JP, Welch WR and Folkman J: Tumor angiogenesis and metastasis-correlation in invasive breast carcinoma. N Engl J Med 324: 1-8, 1991.

33. Folkman J, Merler E, Abernathy C and Williams G: Isolation of a tumor factor responsible for angiogenesis. J Exp Med 133: 275-288, 1971.

34. Hori A, Sasada R, Matsutani E, et al: Suppression of solid tumor growth by immunoneutralizing monoclonal antibody against human basic fibroblast growth factor. Cancer Res 51: 6180-6184, 1991.

35. Inoue K, Perrotte P, Wood CG, Slaton JW, Sweeney P and Dinney CP: Gene therapy of human bladder cancer with adenovirus-mediated antisense basic fibroblast growth factor. Clin Cancer Res 6: 4422-4431, 2000.

36. Davidson JM, Klagsbrun M, Hill KE, et al: Accelerated wound repair, cell proliferation, and collagen accumulation are produced by a cartilage-derived growth factor. J Cell Biol 100: 1219-1227, 1985.

37. Hayek A, Culler FL, Beattie GM, Lopez AD, Cuevas P and Baird A: An in vivo model for study of the angiogenic effects of basic fibroblast growth factor. Biochem Biophys Res Commun 147: 876-880, 1987.

38. Ioannou XP, Gomis SM, Karvonen B, Hecker R, Babiuk LA and van Drunen Littel-van den Hurk S: CpG-containing oligodeoxynucleotides, in combination with conventional adjuvants, enhance the magnitude and change the bias of the immune responses to a herpesvirus glycoprotein. Vaccine 21: 127-137, 2002.

39. Weeratna RD, McCluskie MJ, Xu Y and Davis HL: CpG DNA induces stronger immune responses with less toxicity than other adjuvants. Vaccine 18: 1755-1762, 2000.

40. Kindrachuk J, Jenssen H, Elliott M, et al: A novel vaccine adjuvant comprised of a synthetic innate defence regulator peptide and $\mathrm{CpG}$ oligonucleotide links innate and adaptive immunity. Vaccine 27: 4662-4671, 2009. 